\title{
Safety and Feasibility Study of a Novel Stent-Graft for Thoracic Endovascular Aortic Repair: a Canine Model Experiment
}

Fan Yang1, MD; Jiehua Qiu², PhD; Zeliang Fu³, MD; Yuchen Qiu³, MD; Junrong Luo', MD; Qingyang Xiao', MD; Huabin $\mathrm{Cao}^{1}, \mathrm{PhD}$

\section{Abstract}

Objective: To evaluate the safety and feasibility of a novel stent-graft for thoracic endovascular aortic repair (TEVAR) in a canine model, 9 adult hybrid dogs were used for the experiment.

Methods: All animals were implanted with a novel thoracic aortic stent-graft via femoral artery. Blood sample was collected at pre-operation and 1, 2, 4, 8 and 12 weeks after implantation for hematological examination. Moreover, tissues from randomly selected 4 dogs were subjected to histopathological analysis with the optical microscope after stent-grafts were implanted for 3, 6, 9 , and 12 months respectively. The experimental period lasted for more than 2 years.

Results: A total of 9 stent-grafts were successfully implanted in the canine thoracic aortas and no migration or deformation occurred. Related indicators of blood routine, inflammatory factors, and immunology changes were not significantly $(P>0.05)$, except the white blood cell (WBC) counts in the first week. Moreover, abnormal morphology was not found in all thoracic aortas via histopathological examination. Additionally, all stent-grafts were patent and did not migrate, and there was no thrombus in the lumens of stent-grafts.

Conclusion: The novel thoracic aortic stent-graft made in China was safe and feasible for thoracic endovascular aortic repair in a canine model.

Keywords: Stent-graft. Thoracic Endovascular Aortic Repair. Dogs. Models, Animal. Safety. Feasibility Studies. Aortic Diseases. Endovascular Procedures. Stents.

\begin{tabular}{ll}
\hline Abbreviations, acronyms \& symbols \\
\hline AAA & $=$ Abdominal aortic aneurysm \\
AD & $=$ Aortic dissection \\
C3 & $=$ Complement-3 \\
CRP & $=$ C-reactive protein \\
Hb & $=$ Hemoglobin \\
H\&E & $=$ Hematoxylin and eosin \\
IgG & $=$ Immunoglobulin G \\
IgM & $=$ Immunoglobulin M \\
PLT & $=$ Platelet \\
RBC & $=$ Red blood cell \\
TAA & $=$ Thoracic aortic aneurysm \\
TEVAR & $=$ Thoracic endovascular aortic repair \\
TNF-a & $=$ Tumor necrosis factor-a \\
WBC & $=$ White blood cell \\
\hline
\end{tabular}

'Institute of Animal Population Health, College of Animal Science and Technology, Jiangxi Agriculture University, Jiangxi, P.R. China.

2Department of Vascular Surgery, the Second Affiliated Hospital of Nanchang University, Jiangxi, P.R. China.

${ }^{3}$ APT Medical Inc., Hunan, P.R. China.

This study was carried out at Institute of Animal Population Health, College of Animal Science and Technology, Jiangxi Agriculture University, Jiangxi, P.R. China.

No financial support.

\section{INTRODUCTION}

Aortic dissection (AD) is a life-threatening cardiovascular disease with high mortality ${ }^{[1]}$. Multiple abnormalities have been suggested to contribute to predisposition for this disease, mainly including hypertension, degeneration and genetic disorders ${ }^{[2,3]}$. The natural incidence of AD was 0.5-3.2/100.000/yr $\mathrm{r}^{[4,5]}$, and there are about more than 10 thousand new cases of $A D$ each year in China ${ }^{[6]}$. Meszaros et al. ${ }^{[7]}$ reported that about 50\% patients died within 24 hours and $68.2 \%$ within the first 2 days after admission. Besides, the reporting cases of deaths due to aortic abnormalities including $A D$, thoracic aortic aneurysm (TAA) and abdominal aortic aneurysm (AAA) have accelerated more recently ${ }^{[8]}$.

Traditional surgical management technique for aortic diseases such as AD and TAA is surgical replacement with a prosthetic graft, whereas high postoperative complications and mortality have been described. Parodi et al. ${ }^{[9]}$ firstly reported that endovascular stent-graft treatment of AAA in 1991. Dake et al. ${ }^{[10]}$ used transluminally placed stent-grafts to treat descending

\section{No conflict of interest.}

\section{Correspondence Address:}

Huabin Cao

College of Animal Science and Technology, Jiangxi Agriculture University No. 1101 Zhimin Avenue, Economic and Technological Development District Nanchang 330045, Jiangxi, P. R. China

E-mail: chbin20020804@163.com Article accepted on February $8^{\text {th }}, 2017$. 
TAA in 13 patients over a 24-month period. Endovascular stentgraft is capable of repairing various aortic abnormalities as well as maintaining blood flow and declining the possibility of aortic rupture. Therefore, thoracic endovascular aortic repair (TEVAR) by means of stent-graft has turned out to be a more attractive option than conventional surgical approaches ${ }^{[11,12]}$. However, TEVAR may result in kinking, endoleak, infolding or even stentgraft migration. Stent-graft disconformability and disattachment phenomena at the inner aortic arch radius in juvenile trauma victims have received widespread attention ${ }^{[13,14]}$. Although enormous applications have been found in China, most of stentgrafts for TEVAR come from import. Some Chinese patients cannot afford such high medical fees, and the specifications of the commercially available stent-grafts are unitary, which cannot satisfy the needs of complying with tapering naturally vessel, leading to high rates of long-term complication of endovascular stent-graft's distal end. Thus, it is urgent to independently develop a homegrown stent-graft with various tapers. This evaluation work was carried out to primarily evaluate the safety and feasibility of a novel thoracic aortic stent-graft designed by a company in a canine model.

\section{METHODS}

\section{Compliance with Ethical Standards}

All experimental procedures complied with the criteria in Guide for the Care and Use of Laboratory Animals and Brazilian Guidelines on Care and Use of Animals for Scientific and Teaching Purposes, National Council for Animal Experimentation Control. The institutional ethics committee also approved this study.

\section{Stent-graft System}

The stent-graft, $110 \mathrm{~mm}$ in length and $26 \mathrm{~mm}$ in diameter, is mainly comprised of nickel titanium alloy, polyethylene terephthalate and platinum-iridium alloy. It has characteristics such as good bendability, compliance, adhesion of vessel wall and low profile. The transportation system and delivery system are mainly composed of Teflon, polycarbonate and stainless steel, resulting in higher compliance. Moreover, the minimum size of transportation system is $14 \mathrm{~F}$, while general products' sizes are 6-8 F. In addition, the external sheath of transportation system, merely $4.9 \mathrm{~mm}$ to $6.1 \mathrm{~mm}$ in diameter, can obviously reduce the damage of blood vessel. The markers on stent-graft are used to ensure accurate positioning (Figure 1).

\section{Animals and Treatments}

The non-survival procedures were performed in compliance with national animal welfare laws. Nine adult hybrid dogs (weight

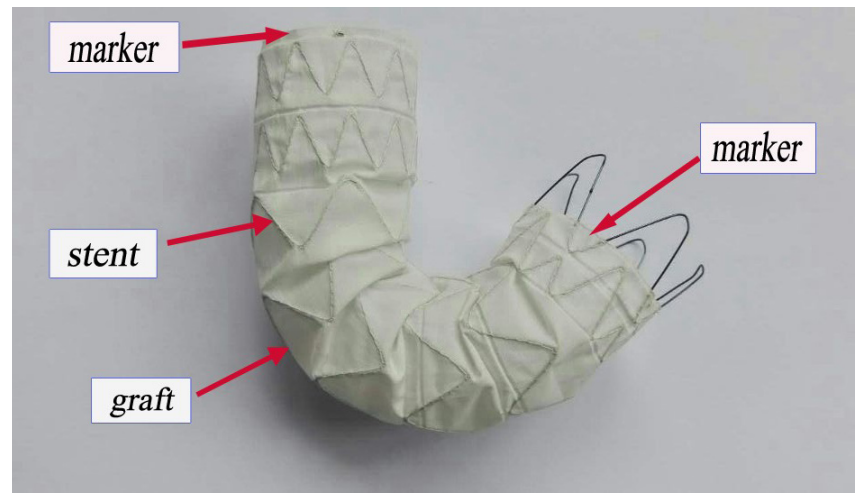

Fig. 1 - Stent-graft system.

25 to $35 \mathrm{~kg}$ ), used in this study, were derived from social donation after physical examination, vaccination and disinsectization performed. All animals were fed with special dog food and also guaranteed free access to water and provided an adequate housing. The dogs were handled and treated in accordance with strict guiding principles of the National Institutes of Health for experimental care and use of animals. The implantations were performed in a month and the experimental period lasted for more than 2 years. The order and time of necropsy are shown in Table 1.

\section{Operation}

The operation was performed at Second Affiliated Hospital of Nanchang University. Dogs were given antibiotics for 3 days, 12 hours of fasting and water deprivation was carried out before surgery. The dogs were given a hypodermic injection of atropine sulfate $(0.01 \mathrm{mg} / \mathrm{kg})$ and etamsylate $(10 \mathrm{mg} / \mathrm{kg})$, respectively. Anesthesia was followed by intravenous propofol (6 mg/kg).

The diameter of thoracic aorta was evaluated through the femoral artery. The heparin saline and contrast media were injected. And then, the loach guide wire and the pigtail catheter were inserted via common femoral artery. The distal end of the pigtail catheter should reach the position of ascending thoracic aorta. Angiography was conducted to measure the diameter of thoracic aorta (Figure 2). Afterwards, $260 \mathrm{~cm}$ in length with curved super-stiff guide wire were sent to the specific location of aortic arch via the pigtail catheter, and then the pigtail catheter and short needle sheath were extracted. Subsequently, the stent-graft system was sent to the desired position via the super-stiff guide wire. Finally, the stent-graft was unfolded and affixed to the vascular wall when it reached the desired position. Angiography was repeated to evaluate the effect of implantation (Figure 2).

Table 1. Order and time of necropsy of dogs.

\begin{tabular}{c|c|c|c|c|c}
\hline Dog & $\mathbf{1 , 2}$ & $\mathbf{3 , 4}$ & $\mathbf{5 , 6}$ & $\mathbf{7 , 8}$ & $\mathbf{9}$ \\
\hline $\begin{array}{c}\text { Time of necropsy } \\
\text { (after surgery) }\end{array}$ & 3 months & 6 months & 9 months & 12 months & $>12$ months \\
\hline
\end{tabular}



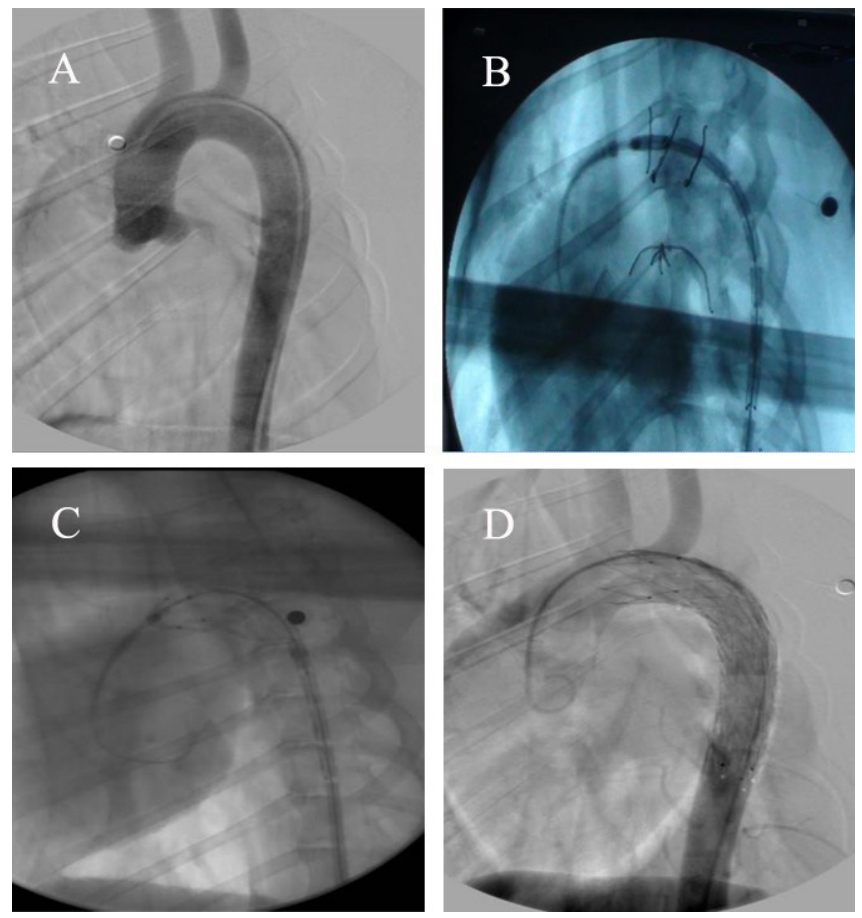

Fig. 2 - Angiography. (A) Preoperative angiography image. (B) The delivery system reached the present position. (C) The release of stentgraft firstly. (D) Postoperative angiography image.

\section{Blood Collection}

Blood samples were collected from 9 dogs preoperatively and 1, 2, 4, 8 and 12 weeks after implantation. Two milliliters of blood collected via cephalic vein was used for the examination of blood routine. The remaining blood was allowed to clot, incubated at $37^{\circ} \mathrm{C}$ for 2 hours and the serum was obtained by centrifugation at $1000 \mathrm{~g}$ for 5 minutes at $4^{\circ} \mathrm{C}$. Then the serum was stored at $-20^{\circ} \mathrm{C}$ until analyzed for the examination of inflammatory factors and immunological indexes.

\section{Sacrifice and Tissue Collection}

A complete necropsy was performed on 8 dogs at clinical veterinary medicine laboratory in the College of Animal Science and Technology Jiangxi Agricultural University. Histopathological examination was carried out on 4 dogs randomly selected 3 , 6, 9 and 12 months after implantation. The thoracic aorta was dissected and washed with saline, then fixed in 10\% neutral buffered formalin (3-5 days). Formalin-fixed samples were routinely processed, embedded in paraffin, sectioned at $5 \mu \mathrm{m}$, stained with hematoxylin and eosin (H\&E), and pathological sections were observed using an optical microscope and photographs were taken.

\section{Statistical Analysis}

The results were presented as mean \pm SD. The statistical analysis included SPSS version 17.0 (SPSS Inc., Chicago, IL, USA), Student's t-test, GraphPad Prism 5.0 (GraphPad Inc., La Jolla, CA, USA). A $P$ value of less than 0.05 was considered significant.

\section{RESULTS}

No animal was killed during this experiment, except intentional sacrifice. Furthermore, no abnormality was found in habits and lifestyle on all animals before necropsy. The ninth animal was kept alive for late follow-up and it is showing good evolution.

\section{Results of the Blood Routine}

As shown in Figure 3, white blood cell (WBC) counts at the first week after implantation were significantly increased $(P<0.05)$, in comparison with those at preoperative period, while there was no significant difference $(P>0.05)$ among preoperative days and the other days (Figure $3 \mathrm{~A}$ ). Changes in red blood cell (RBC) counts, hemoglobin $(\mathrm{Hb})$ levels and platelet (PLT) counts were not significant $(P>0.05)$ among pre- and postoperative periods, and all indicators were kept in normal range in the experimental period (Figures 3B, C and D).

\section{Results of Inflammatory Factors}

As shown in Figure 4, the levels of tumor necrosis factor-a (TNF-a) (Figure 4A) and C-reactive protein (CRP) (Figure 4B) were kept in normal range during the experimental period and there was no significant difference $(P>0.05)$ among pre- and postoperative periods.

\section{Results of Immunological Indexes}

The changes of immunological indexes are shown in Figure 5. No significant difference $(P>0.05)$ in the levels of complement-3 (C3), immunoglobulin $\mathrm{G}$ (lgG) and immunoglobulin M (lgM) among pre- and post-operative periods were observed and all indicators were kept in normal range (Figures 5A, B and C).

\section{Autopsy Findings}

All stent-grafts were patent and did not migrate. As shown in Figure 6, the inner surface of stent-graft was smooth, suggesting satisfactory neointimal coverage and the adventitia appeared essentially normal. Additionally, there was no thrombus in the lumens of stent-grafts. Endothelialization was found in the thoracic aorta implanted with stent-grafts, and perivascular erosion was not observed.

\section{Histopathological Examination}

The histopathological results of thoracic aorta with no stentgraft are shown in Figure 7. All the tissue slices showed normal morphology. No inflamed cells (mononuclear cell, macrophage, etc.) and degeneration or necrosis were found. Additionally, the histopathological results in the thoracic aorta implanted with stent-graft are shown in Figure 8. All the tissue slices showed no abnormal sign. Abnormal cells and thoracic aorta thickening were not observed.

\section{DISCUSSION}

The application of endovascular repair by means of stentgraft has been demonstrated to be a safe and effective treatment 

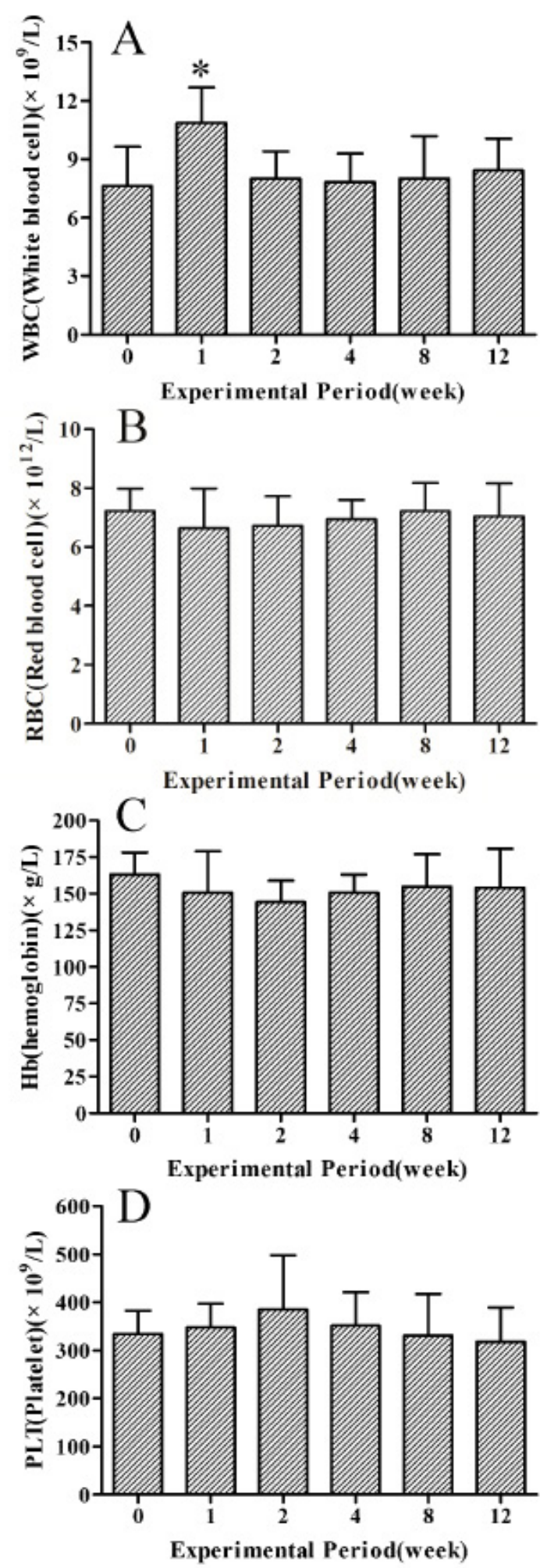

Fig. 3 - Blood routine indexes at pre- and 1,2, 4, 8 and 12 weeks after implantation. Panels A-D show changes of WBC counts, RBC counts, $\mathrm{Hb}$ levels and PLT counts, respectively.

*Donate significant difference $(P<0.05)$. Data are the means \pm SEM $(n=9)$.
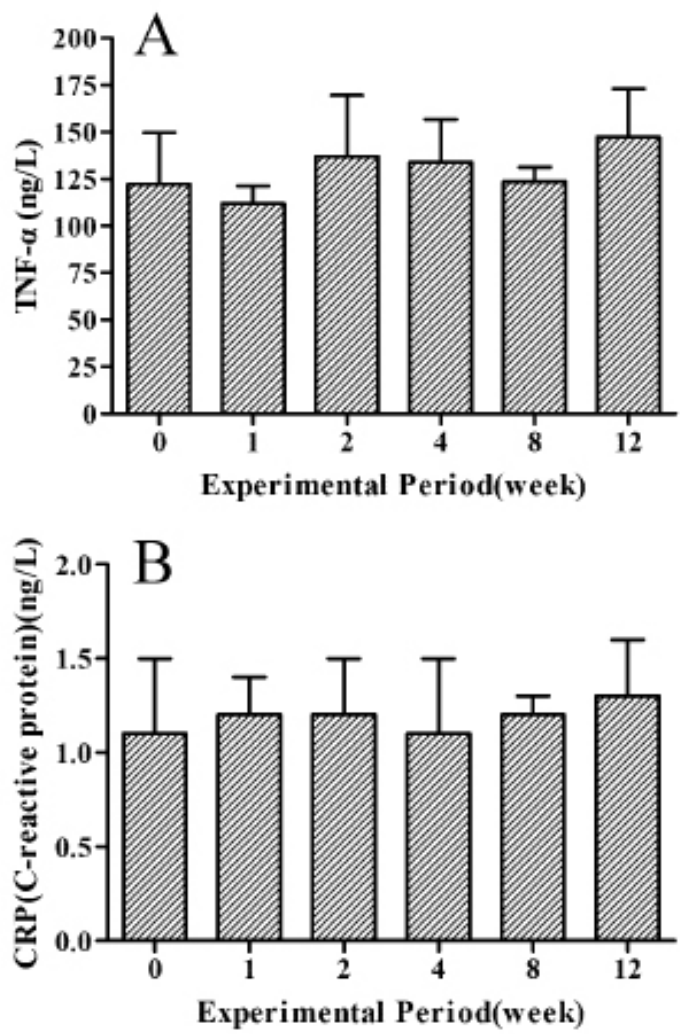

Fig. 4 - Inflammatory factors at pre-and1, 2, 4, 8 and 12 weeks after implantation. Panels A-B show changes of levels of TNF- $a$ and CRP, respectively.

Data are the means \pm SEM $(n=9)$.

for various diseases of thoracic aorta ${ }^{[15,16]}$. This technology has been widely applied in China. The demand for stent-graft is on the increase due to the huge population of patients in China who are suffering from aorta diseases. However, most of stent-grafts in China rely on imports now. Moreover, it is difficult to afford the medical fees for people because China is a developing country. Besides, the specifications of these stent-grafts are unitary, which cannot satisfy the needs of complying with tapering naturally vessel, leading to high rates of long-term complication of endovascular stent-graft's distal end. It is urgent to independently design an effective homegrown stent-graft, which has various tapers and can decline the rates of long-term complication of endovascular stent-graft's distal end. The stent-graft used in our study has good bendability, compliance, adhesion of vessel wall and low profile, and can obviously reduce the damage of blood vessel, which could solve the deficiencies in general products.

In this study, experimental animals were used to evaluate the safety and feasibility of the stent-graft because it was convenient for real-time observation. Dogs (weight 25 to $35 \mathrm{~kg}$ ) were adopted in this research, as the diameter of their artery and its hemodynamics are approximate to human. Furthermore, their tolerance is strong enough to survive long hours of anesthesia and surgery. Canine fibrinolytic system of is more active than the human ${ }^{[17]}$, and their mortality rate and postoperative 

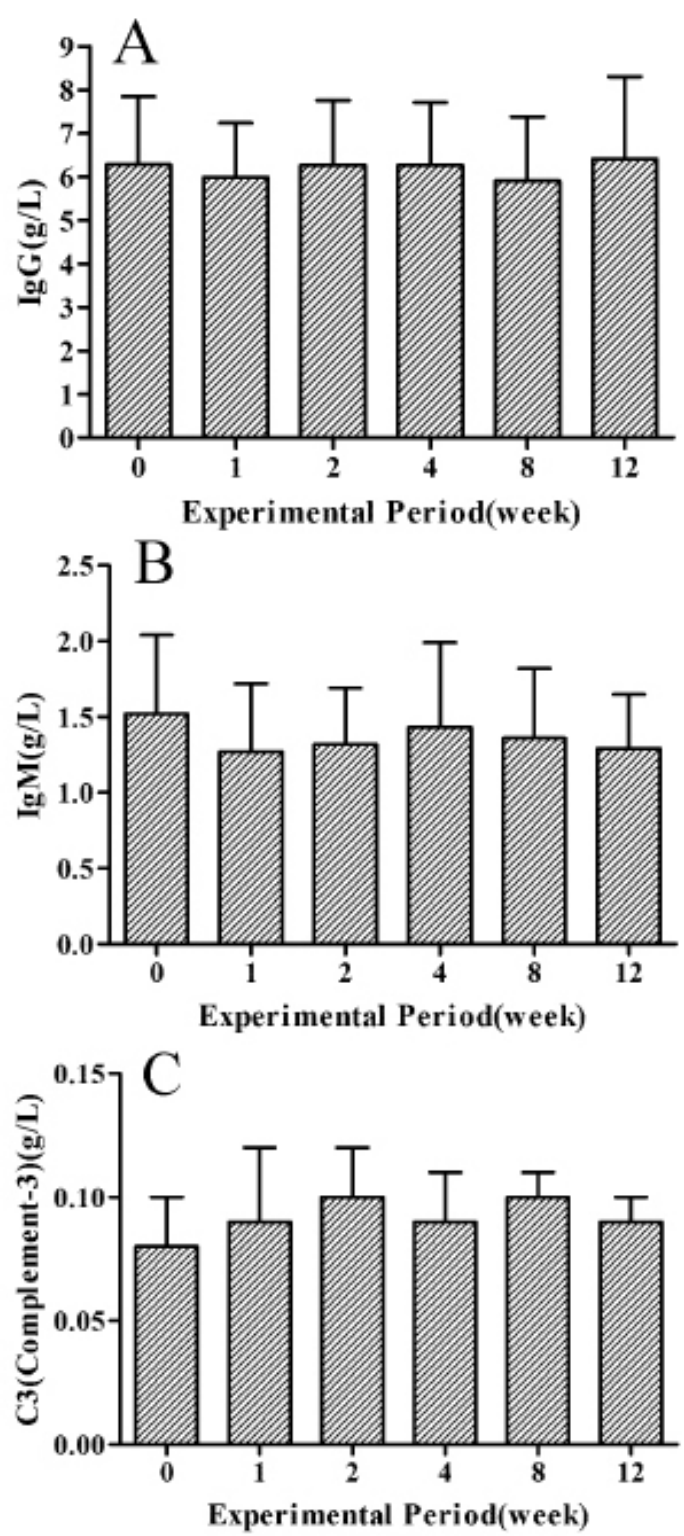

Fig. 5 - Immunological indexes at pre-and 1, 2, 4, 8 and 12 weeks after implantation. Panels A-C show changes of levels of $\mathrm{C} 3, \mathrm{lg} \mathrm{G}$ and Ig $M$, respectively.

The data are the means $\pm \operatorname{SEM}(n=9)$.

complications are much lower than other animals.

Aortic abnormalities such as AD and TAA are harmful diseases with high mortality in emergencies. Endovascular stentgrafts not only could repair various aortic abnormalities, but also maintain blood flow and decline the possibility of aortic rupture. However, there were plenty of problems of early first-generation stent-grafts, such as vascular injury, ascending aortic dissection or aortic penetration from struts, stroke with insertion, graft collapse, endovascular leaks, graft material failure, continued aneurysm expansion or rupture, and migration or kinking ${ }^{[14]}$. Besides, inflammation and rejection are also worth of concerning

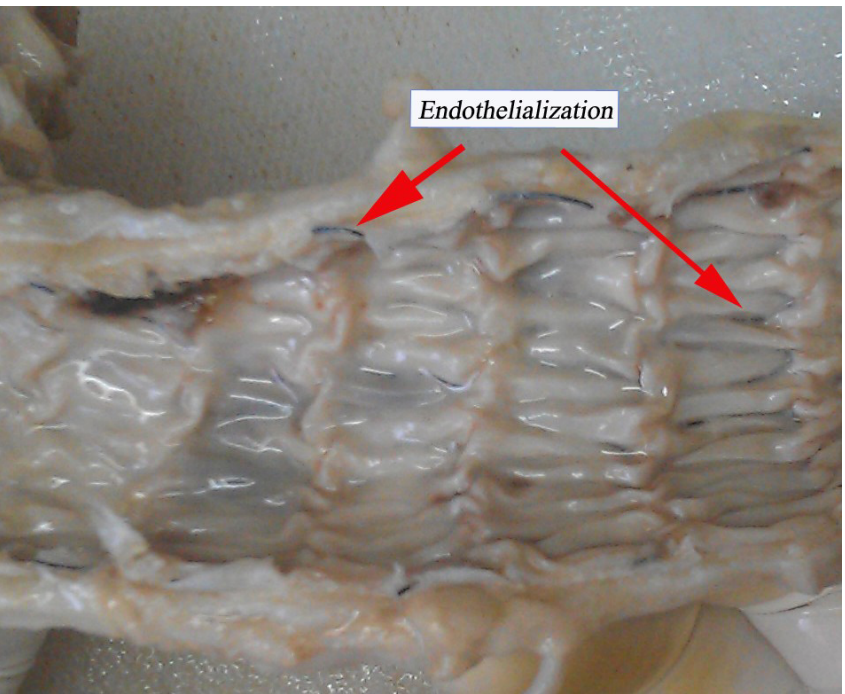

Fig. 6 - Thoracic aorta implanted with stent-graft.

in complication. In this study, the obvious increase of WBC counts at the first week after the implantation, while there was no remarkable difference in other days, reflected inflammation caused by surgery, which could also be demonstrated by the results of inflammation factor. However, it had been improved significantly after using antibiotic. The results of immunological indexes revealed that rejection was not obvious in vivo. Some innovative studies on endovascular repair in animal model have been conducted to study aortic diseases, but they were shortterm studies ${ }^{[18,19]}$. All dogs had stent-grafts implanted successfully in this study. Focus should be attached to the materials of stentgraft in implantation, as well as the importance of surgery itself. Multiple reasons have been confirmed to contribute to fail, mainly including anesthesia, intubation failure, hemorrhage, postoperative infection and improper nursing care.

In our study, the autopsy results showed that the stent-graft could fit the vessel wall of thoracic aorta well. The formation of intima on the inner surface of the bare stent and complete endothelialization of stent-graft surface were observed. The histopathological results also showed that neointima had formed and adventitia appeared essentially normal. The results demonstrated that the stent-graft had high histocompatibility and sealability and had not induced inflammation and calcification, which were consistent with majority relevant reports ${ }^{[20,21]}$. Additionally, the experimental period was more than 2 years, so that the long-term dynamic changes could be distinctly observed, which further demonstrated the safety of stent-graft.

In short, further research is still needed before final clinical application.

\section{CONCLUSION}

In the present study, the thoracic aortic stent-graft made in China was safe and feasible for TEVAR in a canine model.

\section{ACKNOWLEDGEMENT}

We thank all the doctors and students for their assistance in the development of this study. 


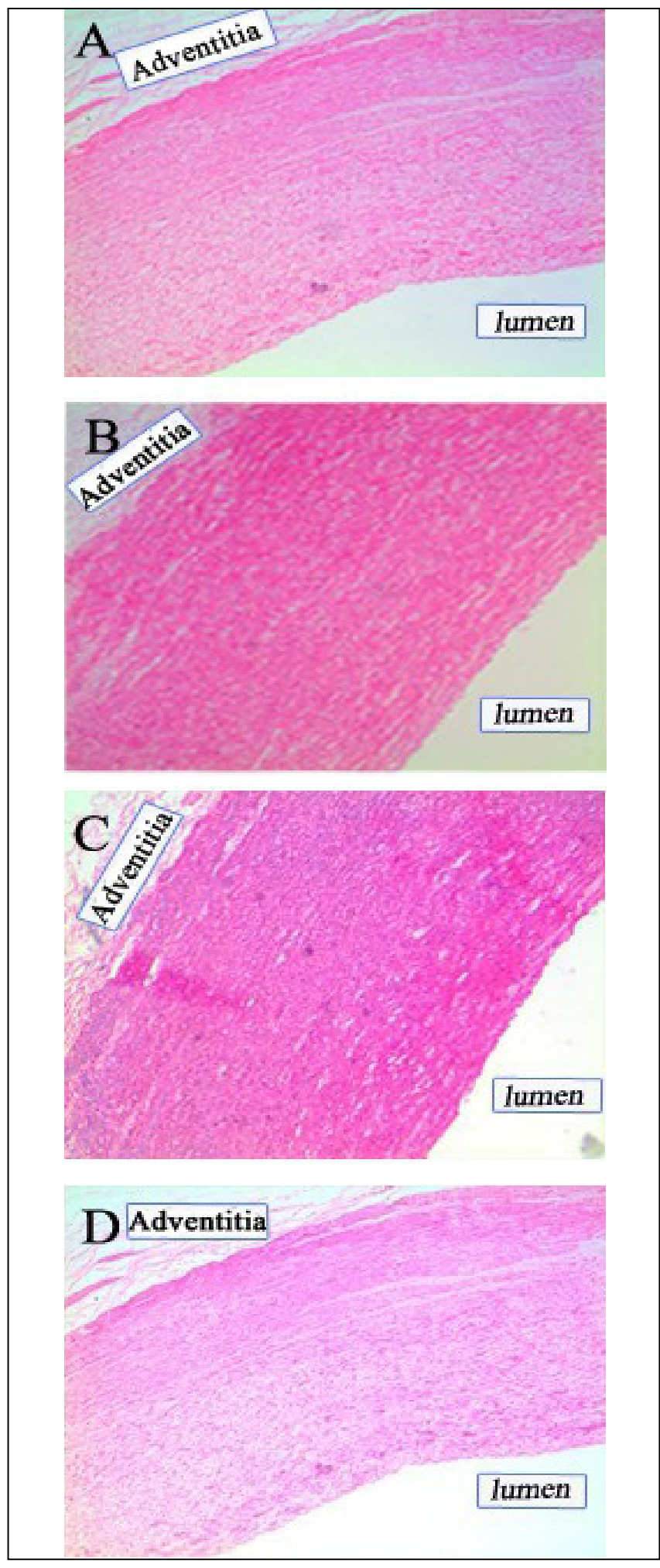

Fig. 7 - Histopathological changes in thoracic aorta with no stent-graft. (A) Thoracic aorta of 3 months after implantation. (B) Thoracic aorta of 6 months after implantation. (C) Thoracic aorta of 9 months after implantation. (D) Thoracic aorta of 12 months after implantation. Magnification, $\times 100$.

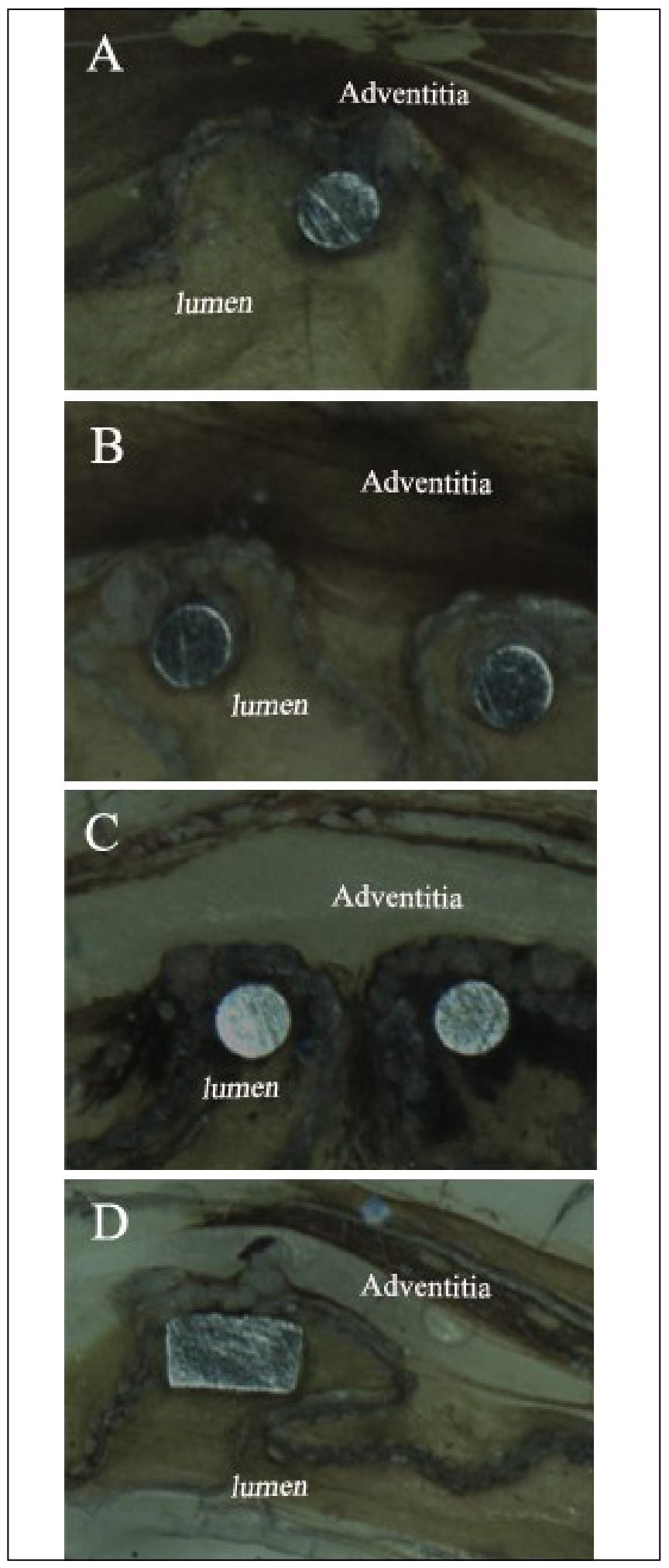

Fig. 8 - Histopathological changes in thoracic aorta implanted with stent-graft. (A) Thoracic aorta of 3 months after implantation. (B) Thoracic aorta of 6 months after implantation. (C) Thoracic aorta of 9 months after implantation. (D) Thoracic aorta of 12 months after implantation. Magnification, $\times 100$. 


\section{Authors' roles \& responsibilities}

FY Design and draft of the work; final approval of the manuscript version to be published

JQ Draft of the work and review it critically for important intellectual content; final approval of the manuscript version to be published

ZF Contributions to the analysis and interpretation of data for the work; final approval of the manuscript version to be published

YQ Contributions to the analysis and interpretation of data for the work; final approval of the manuscript version to be published

JL Calibration; final approval of the manuscript version to be published

QX Calibration; final approval of the manuscript version to be published

HC Design and draft of the work; final approval of the manuscript version to be published

\section{REFERENCES}

1. Seguchi M, Wada H, Sakakura K, Nakagawa T, Ibe T, Ikeda N, et al. Circadian variation of acute aortic dissection. Int Heart J. 2015;56(3):324-8.

2. Guo DC, Papke CL, He R, Milewicz DM. Pathogenesis of thoracic and abdominal aortic aneurysms. Ann NY Acad Sci. 2006;1085:339-52.

3. Sato F, Kitamura T, Kongo M, Okinaka T, Onishi K, Ito M, et al. Newly diagnosed acute aortic dissection: characteristics, treatment modifications, and outcomes. Int Heart J. 2005;46(6):1083-98.

4. Khan IA, Nair CK. Clinical, diagnostic, and management perspectives of aortic dissection. Chest. 2002;122(1):311-28.

5. Svensjo S, Bengtsson H, Bergqvist D. Thoracic and thoracoabdominal aortic aneurysm and dissection: an investigation based on autopsy. Br J Surg. 1996;83(1):68-71.

6. Jiang X, Liu G, Liu L. The research development of aortic dissection. Chinese J Hypertension. 2002;10(2):82-5.

7. Meszaros I, Morocz J, Szlavi J, Schmidt J, Tornoci L, Nagy L, et al. Epidemiology and clinicopathology of aortic dissection. Chest. 2000;117(5):1271-8.

8. Luo J, Liu H. The interpretation of the guideline for diagnosis and

management of aortic diseases from ESC in 2014. South China J Cardiovasc Dis. 2014;20(6):691-6.

9. Parodi JC, Palmaz JC, Barone HD. Transfemoral intraluminal graft implantation for abdominal aortic aneurysms. Ann Vasc Surg. 1991;5(6):491-9.

10. Dake MD, Miller DC, Semba CP, Mitchell RS, Walker PJ, Liddell RP. Transluminal placement of endovascular stent-grafts for the treatment of descending thoracic aortic aneurysms. N Engl J Med. 1994;331(26):1729-34.

11. Kouchoukos NT, Bavaria JE, Coselli JS, De la Torre R, Ikonomidis JS, Karmy-Jones RC, et al. Guidelines for credentialing of practitioners to perform endovascular stent-grafting of the thoracic aorta. J Thorac Cardiovasc Surg. 2006;131(3):530-2.

12. Orend KH, Zarbis N, Schelzig H, Halter G, Lang G, Sunder-Plassmann L. Endovascular treatment (EVT) of acute traumatic lesions of the descending thoracic aorta: 7 years' experience. Eur J Vasc Endovasc Surg. 2007;34(6):666-72.

13. Sunder-Plassmann L, Orend KH. Stentgrafting of the thoracic aortacomplications. J Cardiovasc Surg (Torino). 2005;46(2):121-30.

14. Svensson LG, Kouchoukos NT, Miller DC, Bavaria JE, Coselli JS, Curi MA, et al. Expert consensus document on the treatment of descending thoracic aortic disease using endovascular stent-grafts. Ann Thorac Surg. 2008;85(1 Suppl): S1-41.

15. Cheng D, Martin J, Shennib H, Dunning J, Muneretto C, Schueler S, et al. Endovascular aortic repair versus open surgical repair for descending thoracic aortic disease: a systematic review and meta-analysis of comparative studies. J Am Coll Cardiol. 2010;55(10):986-1001.

16. Shu C, He H, Li QM, Li M, Jiang XH, Luo MY. Endovascular repair of complicated acute type-B aortic dissection with stentgraft: early and mid-term results. Eur J Vasc Endovasc Surg. 2011;42(4):448-53.

17. Y X. Research advancement of aneurysm model. Tianjin Med J. 2000;28(8):510-2.

18. Kim SP, Lee HC, ParkTS, Ahn JH, Lee HW, Park JH, et al. Safety and efficacy of a novel, fenestrated aortic arch stent graft with a preloaded catheter for supraaortic arch vessels: an experimental study in Swine. J Korean Med Sci. 2015;30(4):426-34.

19. Li W, Xu K, Zhong H, Ni Y, Bi Y. A new unibody branched stent-graft for reconstruction of the canine aortic arch. Eur J Vasc Endovasc Surg. 2012;44(2):139-44.

20. Lambert AW, Williams DJ, Budd JS, Horrocks M. Experimental assessment of proximal stent-graft (InterVascular) fixation in human cadaveric infrarenal aortas. Eur J Vasc Endovasc Surg. 1999;17(1):60-5.

21. Shin CK, Rodino W, Kirwin JD, Ramirez JA, Wisselink W, Papierman G, et al. Histology and electron microscopy of explanted bifurcated endovascular aortic grafts: evidence of early incorporation and healing. J Endovasc Surg.. 1999;6(3):246-50. 